\title{
BMJ
}

\section{Euthanasia and other end of life decisions and care provided in final three months of life: nationwide retrospective study in Belgium}

\author{
Lieve Van den Block, professor of communication and education in general practice, and postdoctoral \\ researcher, ${ }^{1,2}$ Reginald Deschepper, anthropologist and professor of critical care, ${ }^{1,6}$ Johan Bilsen, professor of \\ public health, ${ }^{1,4}$ Nathalie Bossuyt, researcher, ${ }^{3}$ Viviane Van Casteren, senior researcher, ${ }^{3}$ Luc Deliens, \\ professor of public health and palliative care ${ }^{1,5}$
}

Vrije Universiteit Brussel, End-ofLife Care Research Group, Laarbeeklaan 103, 1090 Brussels, Belgium

${ }^{2}$ Vrije Universiteit Brussel, Department of General Practice, 1090 Brussels, Belgium

${ }^{3}$ Scientific Institute of Public Health, Department of Epidemiology, 1040 Brussels, Belgium

${ }^{4}$ Vrije Universiteit Brussel, Department of Public Health, 1090 Brussels, Belgium

${ }^{5}$ Department of Public and Occupational Health, EMGO Institute for Health and Care Research, VU University Medical Centre, 1007 MB Amsterdam, Netherlands

${ }^{6}$ Vrije Universiteit Brussel, Department of Critical Care, 1090 Brussels, Belgium

Correspondenceto: LVandenBlock Ivdblock@vub.ac.be

Cite this as: BMJ 2009;339:b2772 doi:10.1136/bmi.b2772

\section{ABSTRACT}

Objective To explore the relation between the care provided in the final three months of life and the prevalence and types of end of life decisions in Belgium. Design Two year nationwide retrospective study, 2005-6 (SENTI-MELC study).

Setting Data collection via the sentinel network of general practitioners, an epidemiological surveillance system representative of all general practitioners in Belgium. Subjects 1690 non-sudden deaths in practices of the sentinel general practitioners.

Main outcome measures Non-sudden deaths of patients (aged $>1$ year) reported each week. Reported care provided in the final three months of life and the end of life decisions made. Multivariable regression analysis controlled for age, sex, cause, and place of death.

Results Use of specialist multidisciplinary palliative care services was associated with intensified alleviation of symptoms (odds ratio $2.1,95 \%$ confidence interval 1.6 to 2.6), continuous deep sedation forgoing food/fluid (2.9, 1.7 to 4.9), and the total of decisions explicitly intended to shorten life $(1.5,1.1$ to 2.1$)$ but not with euthanasia or physician assisted suicide in particular. To a large extent receiving spiritual care was associated with higher frequencies of euthanasia or physician assisted suicide than receiving little spiritual care (18.5, 2.0 to 172.7$)$.

Conclusions End of life decisions that shorten life, including euthanasia or physician assisted suicide, are not related to a lower use of palliative care in Belgium and often occur within the context of multidisciplinary care.

\section{INTRODUCTION}

Several studies from the United States, Europe, and Australia have confirmed that death is often preceded by medical end of life decisions aimed at having or taking into account a life shortening effect. ${ }^{1-6}$ These decisions have been classified as non-treatment decisions with a possible or certain life shortening effect, intensified alleviation of symptoms with a possible life shortening effect, euthanasia, physician assisted suicide, or the use of lethal drugs without the patient's explicit request. Additionally, the practice of continuous deep sedation until death often occurs, which is much debated because of its unclear effects on life shortening. ${ }^{7}$

The position of these decisions within the context of end of life care, however, is far from clear. There is much debate on what is and is not morally acceptable as part of good end of life care. Viewpoints vary between those who think that life shortening is never acceptable or perhaps only as an unintended side effect ("double effect" principle) and those who find explicit life shortening acceptable and sometimes even desirable if careful practice is followed, such as shared decision making. ${ }^{8-10}$ Most discussion concerns the administration (euthanasia), supply, or prescription (physician assisted suicide) of lethal drugs to end a patient's life on his or her explicit request. Some argue that a request for euthanasia or physician assisted suicide is a possible positive outcome of the provision of palliative care, while others are concerned that requests for euthanasia are the result of the absence of access to palliative care. ${ }^{8-11}$ According to the World Health Organization "palliative care should neither hasten nor postpone death," $" 12$ and the ethics taskforce of the European Association of Palliative Care states that "euthanasia is not part of the responsibility of palliative care." 13

Previous studies have focused on attitudes of physicians, the estimation of incidence rates, characteristics of the decision making process, or characteristics of patients and physicians involved in end of life practices. ${ }^{1-61114-17}$ The relation between end of life decision making and the provision of end of life care has not been investigated in large scale studies.

Medical practice in Belgium, with its law on euthanasia ${ }^{18}$ and well developed palliative care available free of charge for all patients and distributed evenly across the whole country, ${ }^{19-21}$ makes it possible to study this highly controversial issue. In Belgium, specialist multidisciplinary palliative care teams advise, support, and help primary or regular care 
givers in caring for dying individuals in every care setting. Contrary to the United Kingdom, there are no clinical specialists trained in palliative care in Belgium. A set of royal and ministerial decrees and a law on palliative care have set out a comprehensive organisational framework for palliative care, placing emphasis on the integration of palliative care in general health care. ${ }^{19-21}$ Since 2002 Belgium has also had a law regulating euthanasia, defining euthanasia as intentionally terminating life by a physician on a patient's explicit request. ${ }^{18}$ The position of physician assisted suicide is legally unclear, but cases of assisted suicide attended by a physician are treated the same as euthanasia cases when reported to the Belgian Federal Control and Evaluation Commission Euthanasia.

We investigated how prevalence and types of medical end of life decisions with a possible or certain life shortening effect are related to the care provided in the final three months of life. We studied the provision of end of life care by looking at the involvement of formal and informal care givers, including specialist multidisciplinary palliative care, the goal of the patients' treatment in the final months of life, the extent to which physical, psychosocial, and spiritual care is delivered, and the patients' place of death as a structural care component. We categorised and defined end of life decisions using a pre-existing internationally validated conceptual framework. ${ }^{12}$

\section{METHODS}

Study design, setting, and participants

Because general practitioners are pivotal providers of health care in Belgium (95\% of the population, including residents in care homes, have a regular general practitioner, whom they consult on a regular basis), ${ }^{22}$ we collaborated with the nationwide sentinel network of general practitioners to obtain a population based sample of deaths in Belgium. This network, operational since 1979 , is a reliable surveillance system for various health related epidemiological data. ${ }^{2324}$ In 2005 and 2006 it consisted of 181 and 174 practices, respectively, representative of all 10578 Belgian general practitioners in terms of age, sex, and region. ${ }^{2325}$

From 1 January 2005 to 31 December 2006, this network participated in the SENTI-MELC study, a two year nationwide mortality retrospective study designed to monitor end of life care. ${ }^{24}$ Each week the general practitioners of the sentinel network registered all deaths of patients aged over 1 year in their practice (certified deaths and deaths of which they were informed afterward). They registered each death immediately after being informed, using a standardised form. Hospital specialists informed general practitioners if patients died in hospital.

To identify a sample of dying people for whom the provision of end of life care or end of life decision making were relevant considerations, we selected all nonsudden deaths, excluding all deaths that occurred "suddenly and totally unexpectedly" as judged by the general practitioner. ${ }^{1224}$

\section{Data collection}

The first part of the registration form surveyed characteristics of all registered patients (age, sex, underlying cause of death). For patients who had died non-suddenly, general practitioners filled in a second part measuring place of death (home, care home (elderly or nursing home), hospital, inpatient palliative care unit) as a structural care component, and the following aspects of care provided in the final three months of life:

- Involvement of general practitioners, clinical specialists, or informal carers (not, sometimes, or often involved)

- Presence of a specialist multidisciplinary palliative care service (yes or no). In Belgium these services include homecare or care home teams, mobile hospital, or palliative day care teams, all comprising multidisciplinary teams consulting regular care givers, and inpatient palliative care units - that is, home replacing care settings delivering multidisciplinary palliative care

- Main goal of patient's treatment as judged by the general practitioner, in the last week of life and second to fourth week and second to third month before death: cure, prolonging life, or comfort/ palliation

- Content of end of life care in the last week of life and second to fourth week and second to third month before death (the extent to which care delivered by the general practitioner or other carers was directed at physical problems, psychosocial care, or spiritual care - that is, existential, religious). These three palliative care domains, described by the World Health Organization, ${ }^{12}$ were judged on a five point Likert scale $(1=$ not or to small extent to $5=$ to large extent).

Additionally, we surveyed whether or not end of life decisions with possible or certain life shortening effect, taken by the responding general practitioner or by another physician, preceded the patient's death. These included non-treatment decisions taking into account or explicitly intending hastening of death; intensified alleviation of pain or other symptoms taking into account or co-intending hastening of death; administering (euthanasia), supplying, or prescribing (physician assisted suicide) drugs with the explicit intention of hastening death on the patient's explicit request; and administering life ending drugs without the patient's explicit request. Physicians themselves judged the life shortening effect of the decisions made. We also asked whether the patient had been deeply and continuously sedated or in a coma until death with drugs such as benzodiazepines or barbiturates (continuous deep sedation), and, if so, whether artificial food or fluid was administered or not. We did not measure the life shortening effect of continuous deep sedation in this study. The wording of all 
questions and classification of practices was identical to that used in previous incidence studies. ${ }^{12}$

Several procedures were used to ensure data quality: forward-backward translation to develop the instrument for both languages in Belgium (Dutch, French), an extensive pilot study to test the instrument, ${ }^{26}$ automatic follow-up and telephone contact with the physicians to prevent missing data for key variables (such as euthanasia), data entry with consistency, range and skip checks, and double data entry. Full details of methods, the questionnaire, and the first set of results have previously been reported. ${ }^{242728}$

\section{Analysis}

We calculated univariate associations between provision of end of life care and end of life decisions using Fishers' exact tests (StatXact6, Cytel Studio, Cambridge, MA). We performed multivariable logistic regression analysis (SPSS14.0, SPSS, Chicago, IL) using care variables as possible determinants of end of life decisions, controlling for differences in patients' characteristics associated with end of life decision making. For these analyses we compared patients who died after an end of life decision (1) with patients who died without such a decision (0). In the multivariable models, we controlled for age, sex, part of Belgium, and cause of death. We also controlled for place of death, except in the models examining the association between end of life decisions and care from general practitioners or from clinical specialists because of potential multicollinearity problems. We additionally controlled for possible interaction effects between the independent variable and cause of death, which has been found to be highly correlated with end of life care and decision making in previous studies. ${ }^{328}$ If data were missing for an independent variable in more than $10 \%$ of cases, these were also entered as a separate category in a regression model to evaluate whether effects would remain the same.

The independent variables measured in three time frames were combined in an overall score during the final three months of life. Euthanasia and physician assisted suicide were combined because physician assisted suicide was limited to one case. For the analysis of continuous deep sedation, a decision that possibly hastened death could have been made in combination, but we excluded cases in which euthanasia, physician assisted suicide, or administration of life ending drugs without explicit request from the patient occurred in combination.

\section{RESULTS}

The general practitioners reported 2690 deaths, of which $1731(64.3 \%)$ were not sudden. Forty one $(2.4 \%)$ were excluded from the SENTI-MELC study because of missing data. Thus, the results are based on 1690 non-sudden deaths. We compared age, sex, and place of death for the 1032 non-sudden deaths in Flanders with 2128 non-sudden deaths identified in the previous study on end of life practices representative of all deaths in this same part of the country. ${ }^{2}$ There were no significant differences for these characteristics between studies (binomial 95\% confidence interval, exact method). No comparison data were available for the French speaking part of Belgium. Of the 1690 non-sudden deaths, data for possibly life shortening end of life decisions were missing for 46 (of which 43 were hospital deaths), and data for continuous deep sedation were missing for 61 deaths (of which 56 were hospital deaths).

Each year, each general practice reported a mean of five non-sudden deaths (median four, range 0-25). In cases of non-sudden death, 12\% (199) were in patients aged under 65 and 32\% (530) in patients aged 85 or older (table 1). Half (839) were men. Cancer was the cause of death in $43 \%$ (725). Euthanasia or physician assisted suicide, intensified alleviation of symptoms, and continuous deep sedation without food or fluids was more common among patients with cancer than among patients dying from other diseases. Continuous deep sedation and euthanasia or physician assisted suicide were more common among patients aged under 65.

Euthanasia or physician assisted suicide, administration of life ending drugs without explicit request from the patient, and intensified alleviation of symptoms were performed more often in inpatient palliative care units and at home than in care homes or hospitals (table 2). Continuous deep sedation with food or fluids was more prevalent in hospital or in palliative care units than in the other care settings, and non-treatment decisions were made more often in care homes than in other places of death.

Intensified alleviation of symptoms occurred more often in cases where general practitioners or informal carers were involved "sometimes" or "often" than in cases where they were not involved in care. Where multidisciplinary palliative care services were used, intensified alleviation of symptoms was performed in $40 \%$ of cases (253), non-treatment decisions were made in $20 \%$ (128), and continuous deep sedation without food or fluids occurred in $6 \%$ (39). If such a service was not involved, these figures were significantly lower (20\% (184), 14\% (131), and 2\% (21), respectively). In general, decisions that were explicitly intended to shorten the patient's life were taken more often when multidisciplinary palliative care services were used than when they were not (14\% (90) v 10\% (90)). Euthanasia or physician assisted suicide or administration of life ending drugs without explicit request was not significantly associated with use of these services.

Compared with a treatment goal aimed at comfort or palliation, a treatment goal aimed at cure or prolonging life during the last three months of life was related to less use of life ending drugs without explicit request, intensified alleviation of symptoms, non-treatment decisions, and continuous deep sedation without food or fluids. There were a few cases in which treatment was aimed at cure or prolonging life but where an explicit life shortening decision was made. In all cases 
Table 1/Characteristics of study population comprising 1690 cases of non-sudden death* and rates of end of life decisions according to these characteristics. Figures are numbers (row percentage) of those who died

\begin{tabular}{|c|c|c|c|c|c|c|c|c|}
\hline & \multirow[b]{2}{*}{ No (\%) } & \multirow{2}{*}{$\begin{array}{c}\text { Euthanasia } \\
\text { or physician } \\
\text { assisted suicide }\end{array}$} & \multirow{2}{*}{$\begin{array}{c}\text { Life ending drugs } \\
\text { without explicit } \\
\text { request }\end{array}$} & \multirow{2}{*}{$\begin{array}{l}\text { Intensified } \\
\text { symptom } \\
\text { alleviation† }\end{array}$} & \multirow[b]{2}{*}{$\begin{array}{l}\text { Non-treatment } \\
\text { decision } \ddagger\end{array}$} & \multirow{2}{*}{$\begin{array}{l}\text { Total with } \\
\text { explicit life } \\
\text { shortening } \\
\text { intent§ }\end{array}$} & \multicolumn{2}{|c|}{$\begin{array}{c}\text { Continuous deep sedation } \\
\text { until death }\end{array}$} \\
\hline & & & & & & & $\begin{array}{l}\text { Without nutrition } \\
\text { or hydration }\end{array}$ & $\begin{array}{l}\text { With nutrition } \\
\text { and hydration }\end{array}$ \\
\hline \multicolumn{9}{|l|}{ Age (years): } \\
\hline $1-64$ & 199 (12.0) & $7(3.6)$ & $4(2.1)$ & $67(34.5)$ & $28(14.4)$ & 27 (13.9) & 15 (7.9) & $23(12.2)$ \\
\hline $65-84$ & $932(56.1)$ & $11(1.2)$ & 15 (1.7) & 243 (26.9) & $148(16.4)$ & $106(11.7)$ & $31(3.5)$ & $59(6.6)$ \\
\hline$\geq 85$ & 530 (31.9) & $4(0.8)$ & $6(1.2)$ & $135(26.1)$ & $85(16.4)$ & $52(10.1)$ & $16(3.1)$ & $12(2.3)$ \\
\hline P valueף & - & 0.04 & 0.96 & 0.10 & $>0.99$ & 0.49 & 0.02 & $<0.001^{\star \star}$ \\
\hline \multicolumn{9}{|l|}{ Sex: } \\
\hline Male & 839 (49.6) & $11(1.4)$ & $17(2.1)$ & 227 (27.9) & $117(14.4)$ & 95 (11.7) & $33(4.1)$ & $59(7.3)$ \\
\hline Female & $851(50.4)$ & $11(1.3)$ & $9(1.1)$ & $228(27.4)$ & 149 (17.9) & $92(11.1)$ & $29(3.5)$ & $37(4.5)$ \\
\hline P valueף & - & $>0.99$ & 0.12 & 0.87 & 0.052 & 0.70 & 0.61 & 0.02 \\
\hline \multicolumn{9}{|c|}{ Cause of death: } \\
\hline Cancer & $725(43.4)$ & $18(2.6)$ & $14(2.0)$ & 271 (39.1) & $85(12.3)$ & $81(11.7)$ & $38(5.5)$ & $37(5.4)$ \\
\hline CVD & 237 (14.2) & $1(0.4)$ & $0(0.0)$ & $45(19.2)$ & $30(12.8)$ & $17(7.3)$ & $5(2.2)$ & $14(6.1)$ \\
\hline Other & 709 (42.4) & $3(0.4)$ & $12(1.7)$ & $134(19.2)$ & $147(21.0)$ & $86(12.3)$ & $18(2.6)$ & $42(6.1)$ \\
\hline P valueף & - & 0.002 & 0.10 & $<0.001^{\star \star}$ & $<0.001^{\star \star}$ & 0.14 & $0.01^{\star *}$ & $>0.99$ \\
\hline
\end{tabular}

CVD: cardiovascular disease, excluding cardiovascular event.

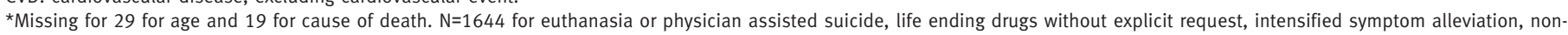
treatment decision, and total with explicit life shortening intent, and 1629 for continuous deep sedation until death.

tWith possible life shortening effect.

$\ddagger$ With possible or certain life shortening effect.

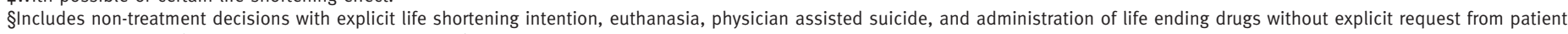

ףFisher's exact tests (univariate analysis between cases).

${ }^{* *}$ Odds ratio remained significant in multivariable logistic regression model correcting for other characteristics of patients.

it concerned non-treatment decisions with an explicit life shortening effect.

Low scores for provision of physical care were related to fewer non-treatment decisions than average or high scores. A low amount of provision of psychosocial care was related to less intensified alleviation of symptoms. Higher scores for spiritual care were associated with higher frequencies of euthanasia or physician assisted suicide.

The multivariable analyses correcting for differences in patients' characteristics (table 3) showed that the chance of dying after euthanasia or physician assisted suicide was significantly higher for patients receiving spiritual care to a (very) large extent than for patients receiving this care to a (very) small extent (odds ratio 18.5, 95\% confidence interval 2.0 to 172.7). Intensified alleviation of symptoms was performed less often if patients died in a hospital than if they died in a palliative care unit. More intensified alleviation of symptoms was associated with higher involvement of general practitioners, informal care givers, and multidisciplinary palliative care services, and with a palliative instead of curative or life prolonging treatment goal. Non-treatment decisions were associated with the involvement of multidisciplinary palliative care services or having a general palliative treatment goal, but only for non-cancer patients. The chance of dying after being sedated continuously until death without food or fluids was higher for patients receiving multidisciplinary palliative care. In general, end of life decisions explicitly intended to shorten life were more common among patients using multidisciplinary palliative care services (odds ratio 1.5) or having a general palliative treatment goal (3) than among patients where these were absent. Continuous deep sedation with food or fluids occurred less often at home or in a care home than in the hospital and if clinical specialists were not involved. Finally, no variables remained significant in the multivariable model for use of life ending drugs without explicit request.

\section{DISCUSSION}

We found several strong associations between medical end of life decisions and care givers' involvement or type of care provided in the final three months of life, even after we controlled for patients' characteristics such as cause of death. ${ }^{328}$ We investigated these associations for the first time, placing euthanasia and other end of life decisions in a broader end of life care context.

\section{Strengths and limitations}

Our data were collected in a country where euthanasia is legalised and where palliative care is well developed throughout. ${ }^{18-21}$ We used a nationwide representative surveillance network of general practitioners not specifically selected for research in end of life care. We considered that the identified sample of non-sudden deaths was representative and the research procedures were high quality (such as weekly registrations, followup to prevent missing data).

The study's limitations include the registration of observational data, which made it possible to study associations but not cause and effect relations. We 
Table $2 \mid$ Rates of end of life decisions in 1690 cases of non-sudden death, according to care provided in final three months of life. Figures are numbers (percentage) of those who died in each category

\begin{tabular}{|c|c|c|c|c|c|c|c|c|}
\hline & \multirow[b]{2}{*}{$\mathrm{No}^{*}(\%)$} & \multirow{2}{*}{$\begin{array}{l}\text { Euthanasia } \\
\text { or physician } \\
\text { assisted suicide }\end{array}$} & \multirow{2}{*}{$\begin{array}{l}\text { Life ending drugs } \\
\text { without explicit } \\
\text { request }\end{array}$} & \multirow{2}{*}{$\begin{array}{l}\text { Intensified } \\
\text { symptom } \\
\text { alleviation† }\end{array}$} & \multirow[b]{2}{*}{$\begin{array}{l}\text { Non-treatment } \\
\text { decision } \ddagger\end{array}$} & \multirow{2}{*}{$\begin{array}{l}\text { Total with explicit } \\
\text { life shortening } \\
\text { intent§ }\end{array}$} & \multicolumn{2}{|c|}{ Continuous deep sedation } \\
\hline & & & & & & & $\begin{array}{l}\text { Without nutrition } \\
\text { or hydration }\end{array}$ & $\begin{array}{c}\text { With nutrition and } \\
\text { hydration }\end{array}$ \\
\hline \multicolumn{9}{|l|}{ Place of death: } \\
\hline Home & $403(23.8)$ & $12(3.0)$ & $9(2.2)$ & $143(35.6)$ & $56(13.9)$ & $47(11.7)$ & $21(5.2)$ & $5(1.2)$ \\
\hline Care home & $452(26.7)$ & $0(0.0)$ & $8(1.8)$ & $130(28.9)$ & $97(21.6)$ & $51(11.3)$ & $9(2.0)$ & $4(0.9)$ \\
\hline Hospital & $665(39.3)$ & $5(0.8)$ & $4(0.6)$ & $117(18.3)$ & $88(13.8)$ & $67(10.5)$ & $23(3.7)$ & $74(11.8)$ \\
\hline $\begin{array}{l}\text { Inpatient palliative } \\
\text { care unit }\end{array}$ & $170(10.1)$ & $5(3.2)$ & $5(3.2)$ & $65(42.2)$ & $25(16.2)$ & $22(14.3)$ & $9(6.0)$ & $13(8.6)$ \\
\hline P valueף & - & $<0.001$ & 0.047 & $<0.001$ & 0.01 & 0.77 & 0.06 & $<0.001$ \\
\hline \multicolumn{9}{|c|}{ Caregivers' involvement in patient care } \\
\hline \multicolumn{9}{|l|}{ General practitioner: } \\
\hline Not involved & $55(3.3)$ & $0(0.0)$ & $1(2.1)$ & $8(16.7)$ & $11(22.9)$ & $8(16.7)$ & $3(6.3)$ & $5(10.4)$ \\
\hline Sometimes & $352(21.3)$ & $7(2.1)$ & $3(0.9)$ & $75(22.6)$ & $42(12.7)$ & 37 (11.1) & $10(3.0)$ & $25(7.6)$ \\
\hline Often & $1248(75.4)$ & $14(1.1)$ & $22(1.8)$ & 369 (29.9) & $212(17.2)$ & $141(11.4)$ & 48 (3.9) & $65(5.3)$ \\
\hline P valueף & - & 0.55 & 0.69 & 0.009 & 0.09 & 0.74 & 0.67 & 0.15 \\
\hline \multicolumn{9}{|l|}{ Clinical specialist: } \\
\hline Not involved & $422(26.1)$ & $4(1.0)$ & $7(1.7)$ & $119(28.5)$ & $87(20.8)$ & $52(12.4)$ & $16(3.8)$ & $3(0.7)$ \\
\hline Sometimes & $576(35.6)$ & $8(1.4)$ & $8(1.4)$ & $175(30.8)$ & $82(14.4)$ & $61(10.7)$ & $17(3.0)$ & $37(6.5)$ \\
\hline Often & $620(38.3)$ & $9(1.5)$ & $11(1.9)$ & $152(25.6)$ & $89(15.0)$ & $71(12.0)$ & $26(4.4)$ & $54(9.2)$ \\
\hline P valueף & - & $>.99$ & $>.99$ & 0.21 & 0.03 & 0.99 & 0.46 & $<0.001$ \\
\hline \multicolumn{9}{|l|}{ Informal carer: } \\
\hline Not involved & $171(10.7)$ & $1(0.6)$ & $1(0.6)$ & $27(16.3)$ & $31(18.7)$ & $19(11.4)$ & $0(0.0)$ & $14(8.5)$ \\
\hline Sometimes & $210(13.2)$ & $4(2.0)$ & $7(3.5)$ & $60(29.7)$ & $37(18.3)$ & $24(11.9)$ & $7(3.4)$ & $7(3.4)$ \\
\hline Often & $1214(76.1)$ & $16(1.3)$ & $18(1.5)$ & $360(30.3)$ & $192(16.1)$ & $140(11.8)$ & $53(4.5)$ & $69(5.8)$ \\
\hline P valueף & - & 0.86 & 0.16 & 0.001 & 0.81 & $>0.99$ & 0.007 & 0.18 \\
\hline \multicolumn{9}{|c|}{ Multidisciplinary palliative care services: } \\
\hline No & $939(58.7)$ & $8(0.9)$ & $13(1.4)$ & $184(20.0)$ & $131(14.2)$ & $90(9.8)$ & $21(2.3)$ & $56(6.1)$ \\
\hline Yes & $661(41.3)$ & $13(2.0)$ & $12(1.9)$ & $253(39.5)$ & $128(20.0)$ & $90(14.1)$ & $39(6.1)$ & $33(5.2)$ \\
\hline P valueף & - & 0.07 & 0.54 & $<0.001$ & 0.003 & 0.01 & $<0.001$ & 0.51 \\
\hline \multicolumn{9}{|l|}{ Treatment goal } \\
\hline Cure or prolonging life & $280(17.6)$ & $0(0.0)$ & $0(0.0)$ & $17(6.2)$ & $24(8.8)$ & $13(4.7)$ & $3(1.1)$ & $35(13.1)$ \\
\hline Comfort/palliation & $487(30.7)$ & $9(1.9)$ & $10(2.1)$ & $156(32.7)$ & $78(16.4)$ & $55(11.5)$ & $18(3.8)$ & $9(1.9)$ \\
\hline Transition ${ }^{\star \star}$ & $752(47.4)$ & $10(1.4)$ & $14(1.9)$ & $257(35.0)$ & $141(19.2)$ & $102(13.9)$ & $35(4.8)$ & $43(5.9)$ \\
\hline Another trajectory & $69(4.3)$ & $1(1.5)$ & $2(2.9)$ & $13(19.1)$ & $9(13.2)$ & $4(5.9)$ & $1(1.5)$ & $4(6.0)$ \\
\hline P valueף & - & 0.13 & 0.049 & $<0.001$ & 0.001 & $<0.001$ & 0.04 & $<0.001$ \\
\hline \multicolumn{9}{|l|}{ Content of care $† \dagger$} \\
\hline \multicolumn{9}{|l|}{ Physical care (score): } \\
\hline $1-2$ & $20(1.3)$ & $0(0.0)$ & $0(0.0)$ & $3(15.0)$ & $2(10.0)$ & $1(5.0)$ & $0(0.0)$ & $0(0.0)$ \\
\hline 3 & 305 (19.9) & $4(1.3)$ & $5(1.7)$ & $102(33.9)$ & $66(21.9)$ & $43(14.3)$ & $15(5.0)$ & $21(7.0)$ \\
\hline $4-5$ & $1211(78.8)$ & $15(1.3)$ & $21(1.8)$ & $333(28.0)$ & $179(15.1)$ & $130(10.9)$ & $42(3.6)$ & $66(5.6)$ \\
\hline P valueף & - & $>0.99$ & $>0.99$ & 0.08 & 0.02 & 0.33 & 0.63 & 0.74 \\
\hline \multicolumn{9}{|l|}{ Psychosocial care score: } \\
\hline $1-2$ & $271(19.7)$ & $0(0.0)$ & $3(1.1)$ & $59(22.2)$ & $40(15.0)$ & $23(8.6)$ & $6(2.3)$ & $14(5.3)$ \\
\hline 3 & $687(49.8)$ & $11(1.6)$ & $13(1.9)$ & $219(32.3)$ & $117(17.2)$ & $87(12.8)$ & $34(5.0)$ & $41(6.1)$ \\
\hline $4-5$ & $421(30.5)$ & $6(1.5)$ & $6(1.5)$ & $127(30.8)$ & $68(16.5)$ & $45(10.9)$ & $16(3.9)$ & $17(4.1)$ \\
\hline P valueף & - & 0.12 & $>0.99$ & 0.01 & $>0.99$ & 0.25 & 0.21 & 0.53 \\
\hline \multicolumn{9}{|l|}{ Spiritual care score: } \\
\hline $1-2$ & $615(56.0)$ & $1(0.2)$ & $10(1.6)$ & $168(27.5)$ & $104(17.0)$ & $64(10.5)$ & $21(3.5)$ & $37(6.1)$ \\
\hline 3 & 377 (34.3) & 7 (1.9) & $8(2.1)$ & $123(32.7)$ & $84(22.3)$ & $58(15.4)$ & $23(6.2)$ & $18(4.8)$ \\
\hline $4-5$ & $107(9.7)$ & $4(3.8)$ & $3(2.9)$ & $31(29.5)$ & $13(12.4)$ & $14(13.3)$ & $2(1.9)$ & $5(4.8)$ \\
\hline P valueף & - & 0.001 & 0.75 & 0.29 & 0.04 & 0.09 & 0.09 & 0.92 \\
\hline
\end{tabular}

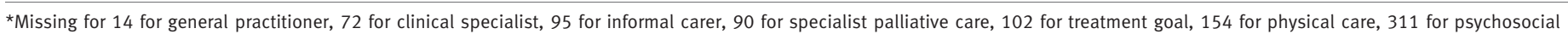
care, 591 for spiritual care.

†With possible life shortening effect.

$\ddagger$ With possible or certain life shortening effect.

§Includes non-treatment decisions with explicit life shortening intention, euthanasia, physician assisted suicide, and life ending drugs without explicit request from patient.

IP values Fisher's exact tests (univariate analysis between cases).

**From cure/prolonging life to comfort/palliation in last months of life.

††1-2=not or to (very) small extent; 3=average; 4-5=to (very) large extent. 
Table 3 |Care provided in final three months of life as possible determinants of end of life decisions, controlled for all patients' characteristics. Figures are odds ratios ( $95 \%$ confidence intervals) from multivariable logistic regression models. Only models where associations were significant in multivariable model are shown

\begin{tabular}{|c|c|c|c|c|c|c|}
\hline & \multirow[b]{2}{*}{$\begin{array}{l}\text { Euthanasia or physician } \\
\text { assisted suicide }\end{array}$} & \multirow[b]{2}{*}{$\begin{array}{l}\text { Intensified alleviation } \\
\text { of symptoms* }\end{array}$} & \multirow[b]{2}{*}{$\begin{array}{l}\text { Non-treatment } \\
\text { decision† }\end{array}$} & \multirow[b]{2}{*}{$\begin{array}{c}\text { Total with explicit } \\
\text { lifeshortening intent } \ddagger\end{array}$} & \multicolumn{2}{|c|}{ Continuous deep sedation } \\
\hline & & & & & $\begin{array}{l}\text { Without nutrition } \\
\text { or hydration }\end{array}$ & $\begin{array}{l}\text { With nutrition } \\
\text { and hydration }\end{array}$ \\
\hline \multicolumn{7}{|c|}{ Place of death (reference=inpatient palliative care unit): } \\
\hline Home & - & - & - & - & - & $0.14(0.05$ to 0.40$)$ \\
\hline Care home & - & - & - & - & - & $0.15(0.05$ to 0.47$)$ \\
\hline Hospital & - & $0.4(0.3$ to 0.7$)$ & - & - & - & - \\
\hline \multicolumn{7}{|c|}{ Care givers' involvement in patient care } \\
\hline \multicolumn{7}{|c|}{ General practitioner (reference=no involvement): } \\
\hline Often & - & $2.4(1.1$ to 5.2$)$ & - & - & - & - \\
\hline \multicolumn{7}{|c|}{ Clinical specialist (reference=no involvement): } \\
\hline Sometimes & - & - & - & - & - & $14.2(3.4$ to 59.6$)$ \\
\hline Often & 一 & 一 & 一 & 一 & 一 & $17.6(4.2$ to 74.0$)$ \\
\hline \multicolumn{7}{|c|}{ Informal carer (reference=no involvement): } \\
\hline Sometimes & - & $1.8(1.1$ to 3.1$)$ & - & - & - & - \\
\hline Often & - & $1.8(1.1$ to 2.8$)$ & - & - & - & - \\
\hline \multicolumn{7}{|c|}{ Multidisciplinary palliative care services (reference=no involvement): } \\
\hline Yes & - & $2.1(1.6$ to 2.6$)$ & $1.8(1.3$ to 2.4$) \S$ & $1.5(1.1$ to 2.1$)$ & $2.9(1.7$ to 4.9$)$ & - \\
\hline \multicolumn{7}{|c|}{ Treatment goal (reference $=$ cure or prolonging life) $\S$} \\
\hline Comfort/palliation & - & 9.1 (5.1 to 16.3$)$ & $2.4(1.5$ to 4.0$) \S$ & $2.6(1.4$ to 4.9$)$ & - & - \\
\hline Transitionף & - & $10.0(5.7$ to 17.4$)$ & 2.9 (1.8 to 4.7$) \S$ & $3.2(1.8$ to 5.9$)$ & - & - \\
\hline Another trajectory & - & $12.9(4.8$ to 34.8$)$ & - & - & - & - \\
\hline \multicolumn{7}{|l|}{ Content of care ${ }^{\star \star}$} \\
\hline \multicolumn{7}{|c|}{ Spiritual care score (reference=score 1-2): } \\
\hline 3 & 9.5 (1.1 to 78.2$)$ & - & $1.5(1.1$ to 2.1$)$ & 一 & - & - \\
\hline 4-5 & 18.5 (2.0 to 172.7$)$ & - & - & - & - & - \\
\hline \multicolumn{7}{|c|}{$\begin{array}{l}\text { *With possible life shortening effect. } \\
\text { †With possible or certain life shortening effect. } \\
\text { †Includes non-treatment decisions with explicit life shortening intention, euthanasia, physician assisted suicide, and life ending drugs without explicit request from patient (no significant } \\
\text { variables). } \\
\text { §Main effect of independent variable no longer significant when interaction between independent variable and cause of death entered in model. Odds ratios significant only for patients } \\
\text { without cancer and not for patients with cancer. } \\
\text { \From cure/prolonging life to comfort/palliation in the last months of life }\end{array}$} \\
\hline
\end{tabular}

also had to rely on general practitioners to report end of life care and decision making. Medical practice in hospitals might have been difficult for general practitioners to judge, especially concerning those aspects that are part of standard practice and generally less often discussed with other professionals, such as intensified alleviation of symptoms. ${ }^{13}$ Results confirmed that missing data were highest for deaths in hospital. Also, some variables measuring provision of care had missing data irrespective of setting, such as spiritual care. ${ }^{28}$ To minimise possible bias we excluded cases with missing data from the analyses and additionally verified whether odds ratios remained significant when we entered cases with missing data as a separate category in the analyses (table 3). Additionally, because of a low number of cases for some decisions, such as euthanasia, the confidence intervals of the odds ratios in the multivariable analyses were large in some cases making it difficult to determine the strength of an association. Finally, we did not measure individual quality of care or outcomes of quality of care (such as a patient's symptom severity), which could make further interpretations possible.

\section{Comparison with other studies and implications}

Our results do not support the concern that euthanasia or physician assisted suicide might be disproportionately chosen by or for patients who do not access palliative care provision. ${ }^{811} \mathrm{We}$ found no indications that euthanasia or physician assisted suicide is performed more often among patients who do not use palliative care in Belgium (such as multidisciplinary palliative care services). On the contrary, euthanasia or physician assisted suicide was considerably more prevalent in inpatient palliative care units than in hospitals or care homes. The effect was not significant in the multivariable analysis, but nonetheless shows that such decisions are often being performed within settings delivering multidisciplinary palliative care. An interesting finding is the strong relation between provision of spiritual care and euthanasia or physician assisted suicide. Receiving spiritual care to a large extent in the final three months of life-which is identified as a critical component of palliative care by the World Health Organization and by many terminal patients and their families ${ }^{12} 29$ - was associated with a higher prevalence of euthanasia or physician assisted suicide 


\section{WHAT IS ALREADY KNOWN ON THIS TOPIC}

Death is often preceded by medical end of life decisions in which the physician aims to have or takes into account a life shortening effect

There is much debate as to whether these decisions can be part of optimal end of life care provision, especially concerning the use of lethal drugs explicitly intended to end a patient's life

\section{WHAT THIS STUDY ADDS}

Use of multidisciplinary palliative care services is associated with a higher incidence of several end of life decisions, including decisions explicitly intended to shorten life

The concern that euthanasia or physician assisted suicide might be disproportionately chosen by or for patients who do not access palliative care services is not supported

Receiving spiritual care to a large extent in the final three months of life is associated with a higher incidence of euthanasia or physician assisted suicide than receiving little or no spiritual care at the end of life

Life shortening end of life decisions often occur within the context of multidisciplinary care in Belgium, and they often coexist with a palliative care philosophy

than receiving little or no spiritual care at the end of life. Although we did not measure the quality of the spiritual care itself, this might mean that its provision helps patients to express their wishes, including wishes for euthanasia, or that physicians being confronted with a request for euthanasia more often communicate about death and dying and thus provide spiritual or existential care in response to the request. The finding supports studies showing that reasons for requesting euthanasia or physician assisted suicide are often not physical but concern issues such as suffering in a general sense, loss of dignity, and loss of autonomy or control. ${ }^{1730}$

Other end of life decisions, such as intensified alleviation of symptoms or even administering life ending drugs without explicit request from the patient, also occurred more often in inpatient palliative care units than in other settings. Furthermore, even after we corrected for population differences the use of specialist multidisciplinary palliative care services across all care settings was associated with a higher incidence of intensified alleviation of symptoms, end of life decisions with explicit life shortening intent in general, and continuous deep sedation while forgoing food or fluid. Possibly, patients using these services more often have complex symptoms at the end of their lives than patients not using these services, which might explain why complex end of life decisions need to be made more often. Even then, however, it is remarkable that such far reaching interventions (such as explicitly death hastening, forgoing food or fluid) are chosen for these patients.

Our findings in Belgium suggest that life shortening end of life decisions, including euthanasia or physician assisted suicide, do not seem to be prevented by the involvement of multidisciplinary palliative care services, which has been a major argument against legalisation of euthanasia. ${ }^{81013}$ End of life decisions and palliative care do not seem incompatible, but if anything seem to reinforce each other.
Although research on the quality of end of life care in Belgium is not available, attributing these findings to a lack of well developed palliative care seems to contradict the fact that Belgium has a long tradition of palliative care integrated in mainstream health care and has no structural or financial barriers for all patients in all care settings. ${ }^{19-2128} \mathrm{~A}$ recent historical-sociological analysis of the development of palliative care and the euthanasia legislation in Belgium also concluded that synergistic coevolution rather than antagonistic or separate evolution has occurred. ${ }^{31}$

Delivery of palliative care might help patients to express their wishes and places importance on patients' autonomy in end of life decision making. Alternately, palliative care might often be initiated when patients make a life shortening request-for instance, using a palliative care filter-a recommendation that has been made by the Federal Palliative Care Federation and the national Caritas network of Catholic healthcare institutions. Furthermore, as not all decisions are made on patients' request, ${ }^{12}$ findings suggest that far-reaching decisions to reduce patients' end-oflife suffering are part of palliative care provision in Belgium.

The extent to which these results hold true for other countries needs to be studied but will probably depend on the legal situation and the customary ethical and moral belief systems within palliative care, medical practice, and the broader society. Although the organisation of palliative care is different, previous studies from Oregon, US, where physician assisted suicide is permitted, also showed that most patients receiving physician assisted suicide were enrolled in hospice care (covered by US Medicare) and that the legalisation of physician assisted suicide has resulted in more hospice referrals and training of physicians in palliative care. ${ }^{17}$

\section{Conclusions and future research}

Life shortening and a philosophy of palliative care do not have to oppose each other; they commonly coexist. Medical end of life decisions including euthanasia or physician assisted suicide are not related to lower use of palliative care in Belgium and often occur within the context of multidisciplinary care. Future studies should try to investigate in what manner palliative care influences end of life decision making and try to establish cause and effect relations. Whether or not requests for life shortening end of life decisions such as euthanasia can be the result of the provision of high quality end of life care is an important unanswered empirical question.

We thank Katrien Drieskens (Vrije Universiteit Brussel) and Sabien Bauwens (Brussels University Hospital) for their contribution in study conception and support in data collection; Johan Vanoverloop (Vrije Universiteit Brussel) for his statistical advice; Jane Ruthven for English editing; Rita De Boodt (Flemish Ministry of Welfare, Public Health and Family) for categorising the cause of death into ICD-10 codes; the participating sentinel general practitioners for providing the study data; and the Flemish Ministry of Welfare, Public Health and Family and the Brussels Observatory of Health and Wellness for giving us access to their death certificate data. 
Contributors: $L V d B, V V C$, and $L D$ conceived and designed the study. $\mathrm{LVdB}, \mathrm{NB}$, and VVC acquired the data, which was analysed by LVdB and NB. LVdB drafted the manuscript and is guarantor. LVdB, RD, VVC, and LD obtained funding. $L V d B, R D, N B$, and $L D$ provided administrative and technical support. LVdB, RD, JB, VVC, and LD supervised the study. Al authors analysed and interpreted the data, critically revised the manuscript for important intellectual content, and approved the final version.

Funding: LVdB is a postdoctoral researcher of the Fund for Scientific Research in Flanders, Belgium. This study was funded by the Research Council of the Vrije Universiteit Brussel in Belgium (project GOA27 2003 2007) and the Institute for the Promotion of Innovation by Science and Technology in Flanders as a Strategic Basic Research project (SBO) (contract SBO IWT 050158) (2006-2010), as part of the Monitoring Quality of End-of-Life Care (MELC) Study. The Belgian Sentinel Network of GPs is supported by the Flemish and Walloon Ministry of Welfare, Public Health and Family. The sponsors had no role in design and conduct of the study, in the collection, analysis, and interpretation of the data, in the writing of the report or in the decision to submit the article for publication. The researchers are independent from the funders. Competing interest: None declared.

Ethical approval: The study protocol was approved by the ethical review board of Brussels University Hospital. All patients and physicians were anonymous.

1 Deliens L, Mortier F, Bilsen J, Cosyns M, Vander Stichele R, Vanoverloop J, et al. End-of-life decisions in medical practice in Flanders, Belgium: a nationwide survey. Lancet 2000 25;356:1806-11

2 Van der Heide A, Deliens L, Faisst K, Nilstun T, Norup M, Paci E, et al. End-of-life decision-making in six European countries: descriptive study. Lancet 2003;362:345-50

3 Van den Block L, Bilsen J, Deschepper R, Van Der Kelen G, Bernheim JL, Deliens L. End-of-life decisions among cancer patients compared with noncancer patients in Flanders, Belgium. J Clin Oncol 2006;24:2842-8.

4 Seale C. National survey of end-of-life decisions made by UK medical practitioners. Palliat Med 2006;20:3-10.

5 Kuhse H, Singer P, Baume P, Clark M, Rickard M. End-of-life decisions in Australian medical practice. Med / Aust 1997:166:191-6.

6 Meier DE, Emmons CA, Wallenstein S, Quill T, Morrison RS, Cassel CK. A national survey of physician-assisted suicide and euthanasia in the United States. N Engl/ Med 1998:338:1193-201.

7 Miccinesi G, Rietjens JA, Deliens L, Paci E, Bosshard G, Nilstun T, et al. Continuous deep sedation: physicians' experiences in six European countries. J Pain Symptom Manage 2006;31:122-9.

8 Hermsen MA, Ten Have HA. Euthanasia in palliative care journals. I Pain Symptom Manage 2002;23:517-25.

9 Quill TE, Dresser R, Brock DW. The rule of double effect-a critique of its role in end-of-life decision making. $N$ Engl J Med 1997;337:1768-71.

10 Seale C, Addington-Hall J. Euthanasia: the role of good care. Soc Sci Med 1995;40:581-7.

11 Emanuel Ej, Fairclough D, Clarridge BC, Blum D, Bruera E, Penley WC, et al. Attitudes and practices of U.S. oncologists regarding euthanasia and physician-assisted suicide. Ann Intern Med 2000;133:527-32.

12 WHO. National cancer control programmes: policies and manageria guidelines. Geneva: World Health Organization, 2002.

13 Materstvedt LJ, Clark D, Ellershaw J, Forde R, Gravgaard AM, Muller-Busch HC, et al. Euthanasia and physician-assisted suicide: a view from an EAPC ethics task force. Palliat Med 2003;17:97-101.

14 Onwuteaka-Philipsen BD, Fisher S, Cartwright C, Deliens L, Miccinesi G, Norup M, et al. End-of-life decision making in Europe and Australia: a physician survey. Arch Intern Med 2006;166:921-9.
15 Hinkka H, Kosunen E, Metsanoja R, Lammi UK, Kellokumpu-Lehtinen P. Factors affecting physicians' decisions to forgo life-sustaining treatments in terminal care. J Med Ethics 2002;28:109-14.

16 Meier DE, Emmons CA, Litke A, Wallenstein S, Morrison RS. Characteristics of patients requesting and receiving physicianassisted death. Arch Intern Med 2003;163:1537-42.

17 Quill TE. Legal regulation of physician-assisted death-the latest report cards. N Engl J Med 2007;356:1911-3.

18 Wet betreffende euthanasie 28 mei 2002 [Law concerning euthanasia May 28, 2002] (in Dutch), Number Bill 2002009590, Brussels, Belgium, Belgisch Staatsblad 22 juni 2002 [Belgian officia collection of the laws June 22, 2002], (2002).

19 Wet betreffende palliative zorg 14 juni 2002 [Law concerning palliative care Belgium June 14, 2002] (in Dutch), Number Bill 002022868, Brussels, Belgium, Belgisch Staatsblad 26 oktober 2002 [Belgian official collection of the laws October 26, 2002], (2002).

20 Clark D, ten Have H, Janssens R. Common threads? Palliative care service developments in seven European countries. Palliat Med 2000;14:479-90.

21 Federale evaluatiecel palliatieve zorg [Federal evaluation cel palliative care]. Evaluatierapport Palliatieve Zorg: overzicht van de uitbouw van de palliatieve zorg in België [Evaluation of Palliative Care: overview of palliative care services in Belgium]. 2005

22 Bayingana K, Demarest S, Gisle L, Hesse E, Miermans PJ, Tafforeau J, et al. Health survey interview, Belgium 2004. Brussels, Belgium: Scientific Institute of Public Health Belgium, Department of Epidemiology; 2006. (Report No D/2006/2505/4, IPH/EPI REPORTS No 2006-035.)

23 Lobet MP, Stroobant A, Mertens R, Van Casteren V, Walckiers D, Masuy-Stroobant G, et al. Tool for validation of the network of sentinel general practitioners in the Belgian health care system. Int J Epidemiol 1987;16:612-8.

24 Van den Block L, Van Casteren V, Deschepper R, Bossuyt N, Drieskens K, Bauwens S, et al. Nationwide monitoring of end-of-life care via the Sentinel Network of General Practitioners in Belgium: the research protocol of the SENTI-MELC study. BMC Palliat Care 2007 8;6:6.

25 Boffin N, Bossuyt N, Van Casteren V. Current characteristics and evolution of the Sentinel General Practitioners: data gathered in 2005 [Huidige kenmerken en evolutie van de peilartsen en hun praktijk. Gegevens verzameld in 2005]. Brussels, Belgium: Scientific Institute of Public Health Belgium; Unit of Epidemiology, 2007. (Report No: IPH/EPI REPORTS No 2007-013.) www.iph.fgov.be/ epidemio/epinl/medvnl/profil_05.pdf

26 Van den Block L, Deschepper R, Drieskens K, Bauwens S, Bilsen J, Bossuyt N, et al. Hospitalisations at the end of life: using a sentine surveillance network to study hospital use and associated patient, disease and healthcare factors. BMC Health Serv Res 2007;7:69.

27 Van den Block L, Deschepper R, Bilsen J, Van Casteren V, Deliens L. Transitions between care settings at the end of life in belgium. JAMA 2007;298:1638-9.

28 Van den Block L, Deschepper R, Bossuyt N, Drieskens K, Bauwens S, Van Casteren V, et al. Care for patients in the last months of life: the Belgian sentinel network monitoring end-of-life care study. Arch Intern Med 2008;168:1747-54.

29 Steinhauser KE, Christakis NA, Clipp EC, McNeilly M, McIntyre L, Tulsky JA. Factors considered important at the end of life by patients, family, physicians, and other care providers. JAMA 2000;284:2476-82.

30 Jansen-van der Weide MC, Onwuteaka-Philipsen BD, van der WG. Granted, undecided, withdrawn, and refused requests for euthanasia and physician-assisted suicide. Arch Intern Med 2005;165:1698-704.

31 Bernheim JL, Deschepper R, Distelmans W, Mullie A, Bilsen J, Deliens L. Development of palliative care and legalisation of euthanasia: antagonism or synergy? BMJ 2008;336:864-7.

Accepted: 21 April 2009 